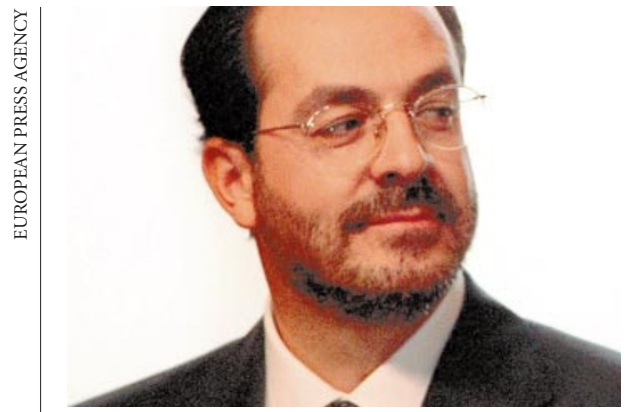

Zecchino: under pressure to revise reform decree.

\section{Italian scientists fear impact of cabinet reshuffle on reforms}

[MUNICH] Italian scientists are reacting nervously to the appointment of Ortensio Zecchino, a lawyer with no experience of scientific issues and a member of the right-wing PPI (Partito populare italiano), as minister for research and universities in the new coalition government.

Last week's ministerial reshuffle followed the collapse of the administration of former prime minister Romano Prodi after losing a no-confidence vote. Zecchino's predecessor was Luigi Berlinguer, a member of the leftwing PDS (Partito democratico della sinistra), who had had broad responsibilities for education. He remains in the cabinet, but his remit has been limited to schools.

The main concern of scientists is the effect the government's fall will have on the major restructuring that Italian research has been facing to increase efficiency (see Nature 386, 208; 1997).

The broad outline of the reforms was approved earlier this year. But pressures of other government business meant that decrees outlining rules for individual organizations - in particular the Italian space agency, the energy and environment agency, and the national research council (CNR) had not been formally approved when the government collapsed.

One of Zecchino's first tasks will be to ensure that the decrees are approved and implemented. But he has the power to make changes to them before this happens, and many researchers are keen that he should introduce revisions to the decree covering the CNR.

A draft of the CNR decree had angered university professors as it eliminated their power over the research council's policymaking and grant distribution. Researchers were also worried that it concentrated that power in the hands of a small group of political appointees (see Nature 394, 712; 1998).

Lucio Bianco, president of the CNR and a member of the same party as Zecchino, is keen that the council should not lose its previous autonomy.

Alison Abbott

\title{
Alarm raised over drop in basic research at NASA
}

[WASHINGTON] Support provided by the US space agency NASA for basic space science research has declined dramatically in the 1990s, according to a report published last week by the National Academy of Sciences' Space Study Board.

The decrease is due partly to a shift towards smaller, cheaper missions that no longer include the cost of data analysis in their budgets. "As the faster-paced style of the agency has begun to take hold," the report says, commitment to research and data analysis (R\&DA) may be getting "blurred or even lost".

The report also finds little evidence of space research moving from NASA laboratories to universities, as was recommended in a report published three years ago.

A panel chaired by Anthony England, an Earth and space scientist at the University of Michigan, spent two years looking at trends in NASA's \$1.5 billion R\&DA budget, and found some "alarming results".

Total NASA research spending grew by 44 per cent from 1991 to 1998, and remained at 3 per cent of the agency's budget. But the numbers are deceptive, as much of the increase was spent on the Earth Observing System satellite data system and on technology development in the space science office.

Meanwhile, 'traditional' research and analysis - grants for university and NASA scientists to do basic research, interpret spacecraft data, and build new instruments - decreased by 22 per cent over the period.

Although funding for NASA grants and the number of grants both went up, the size of a typical award decreased by 25 per cent from 1986 to 1995 . Hardest hit were disciplines such as astronomy, space physics and planetary science, for which the median grant dropped from $\$ 64,000$ to $\$ 59,000$.

Wesley Huntress, director of the Geophysical Laboratory at the Carnegie Institution of Washington, and until recently the head of NASA's space science office, admits that grant awards have become "too damn low".

The median size of Earth science grants remained level from 1986 to 1995 . But one group - the life science and microgravity researchers who design experiments for the space shuttle and space station - saw their median grant rise from $\$ 69,000$ to $\$ 100,000$.

One reason for this rise is that shuttle experimenters often use funding to build expensive flight hardware as well as to conduct research. But life science and microgravity researchers may also have fared better than their colleagues, says England, because "most of NASA's future is tied up in the space station" and the agency has made a point of nurturing that research community.
Other agency-sponsored research does not seem to have the same support. The long-standing criticism that NASA is more interested in flying spacecraft than in doing science remains even more of a concern in the age of cheaper, faster missions.

In the past, large projects, such as Voyager or the Galileo Jupiter mission, dedicated a portion of their budgets for scientists to analyse the data they produced. With less money and shorter lead times, flight projects now barely have the resources to produce raw data, and generally leave the interpretation to NASA's R\&DA programme.

Unlike the more visible and politically saleable flight projects, R\&DA's 'softness' makes it vulnerable to budget cuts, says the academy panel.

The report also addresses the balance between in-house NASA research and extramural grants to universities, which England calls a "very sensitive issue". Even though a 1995 academy report recommended that most scientific research should be conducted outside the agency, researchers at NASA field centres still get most grant money.

NASA scientists receive 40 per cent of the R\&DA budget, and another 30 per cent goes to industry scientists, many of whom are onsite NASA contractors. Only 26 per cent of the money goes to universities.

Reduced NASA funding has already affected the thousands of researchers who depend on agency grants. England says space science is "certainly not a growth field", and may not even be a stable one. The report recommends that NASA should make greater use of training grants for graduate students and "rotate" more outside scientists to serve temporary duty at the agency.

But the panel took pains to emphasize that their report was "not an appeal for an increase in NASA funding". Rather, they say that more attention — including regular outside peer review - should be paid to the balance between flight projects and the science that supports them.

England says the committee had a difficult time finding budget figures that clearly showed NASA's research priorities. The panel had to hire a former NASA budget analyst to help make sense of the numbers. This led to the panel saying that, if NASA cares about its R\&DA programme, it needs to do a better job of tracking how money is spent.

"The fragmented budget structure for R\&DA makes it difficult for the scientific community to understand the content of the programme and for NASA to explain the content to federal budget decision-makers," says the panel.

Tony Reichhardt 